\title{
Allozyme polymorphisms and heavy metal levels in the green-lipped mussel Perna viridis (Linnaeus) collected from contaminated and uncontaminated sites in Malaysia.
}

\begin{abstract}
It has been widely reported that heavy metal contamination in coastal waters can modify the allozyme profiles of marine organisms. Previous studies have recorded elevated metal concentrations in sediments and mussel tissues off Peninsular Malaysia. In the present study, horizontal starch gel electrophoresis was carried out to estimate the levels of allelic variation of the green-lipped mussel, Perna viridis, collected from one contaminated and three relatively uncontaminated sites off Peninsular Malaysia. Fourteen polymorphic loci were observed. In addition, the concentrations of cadmium, copper, lead, mercury and zinc were determined in the sediments and in the soft tissues of the mussels. Mussels from contaminated site, evidenced by high metal pollution indices (MPI) of the sediment and the mussel tissues, showed the highest percentage of polymorphic loci $(78.6 \%)$, while those collected from the uncontaminated sites had lower MPI of the sediment and mussel tissue, and exhibited lower percentages of polymorphic loci (35.7-57.1\%). The population from the contaminated site showed the highest excess of heterozygosity $(0.289)$ when compared to that of the populations from the three uncontaminated sites (0.108-0.149). Allozyme frequencies at the phosphoglucomutase (PGM; E.C. 2.7.5.1) locus also differed between the contaminated and uncontaminated populations. Previous studies have shown that exposure to heavy metals can select or counter-select for particular alleles at this locus. The present results suggest that allozyme polymorphism in $\mathrm{P}$. viridis is a potential biomonitoring tool for heavy metal contamination but further validation is required.
\end{abstract}

Keyword: Perna viridis; Allozymes; Heavy metals; Malaysia. 